\title{
IMPROVING THE PERFORMANCE OF TEMPERATURE CONTROL LOOP IN A CRUDE OIL REFINERY THROUGH THE DIGITAL SIMULATION TECHNIQUE
}

Due to the rapid growth in digital control technology because of their great advantages, it now possible to consider implementing a digital programmable controller for many industerial processes. In this paper some software aspects of digital controllers for temperature control loop in crude oil refineries have been discussed and a new method has been deve-

: loped for rapid tuning of these controllers'parameters through the implementation of digital simulation technique. Different structures of the control loop have been investigated with main emphasis is given to cascaded and feedforward/feedbackward loops. Cascaded structures is shown to reduce the effect of the time delays and yield better dynamic characteristics for the control loop. Preview of the future system disturbance inputs through the feedforward path is shown to be effective to improve the performance of the overall control system. The results of the present investigation indicate that the proposed method is capable to detune the parameters of each controlling action either on-line or off-line with substantial improvement in the dynamic performance of the control loop. 11 lus-: trative examples as well as practical applications are also included.

\section{INTRODUCTION AND OBJECTIVES}

In crude oil refineries, the outlet temperature of the crude oil is the main control variable in oil heaters and the major disturbance results from the change of fuel gas pressure(fuel oil is used as a primary heating sou-: rce and gas is often used as a secondary heating source)supplied to the burners. Temperature control is still the objective of many researchers in this field because the temperature as a manipulated variable, has a slow response speed. So an endless studies havę been introduced to accelerate that response. At lesst a PID action is often essential for temperature control systems to obtain acceptable performance. Cascade control and preview control are also recommended to improve their dynamic behavior.

On the other hand,Zigler-Nichols [1], Rovira method [2] have developed methods: : to detune the controller of a single loop FB system for industerial process which can be presented adequately by second and first order models respectively.

* Engineering Office,Cairo 0il Refining CO., Mostorod,Egypt.

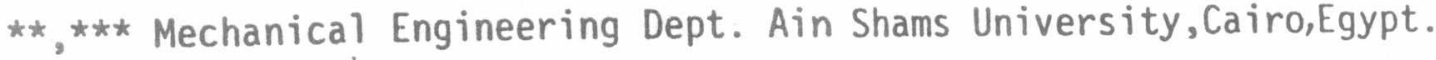


Thus, both methods, if they applied for temperature control systems, will ignore other elements in the system. Overmore $Z N$ method is based on $1 / 4$ decay ratio response which is too oscillatory for temperature control. Dahlin[3] simplification using first order lag plus dead time for the the process is :

not adequate too.

Digital simulation can often serve as very useful tool in assessing poten-i tial improvement with complicated and multiloop systems, and in reaching to a better tuning for controllers parameters. In this paper an application of digital simulation technique to a temperature control of a crude oil heater is:

: presented, which cas be used to obtain some guide lines, if there is any, for controller tuning.

\section{MODELLING}

The dynamic mathematical model of all elements in the system is based on the: : assumption that all elerients are described by a set of linearized equations. since the control system of crude $0 i 1$ heaters may be considered as a regulatory control system because the set point of the process is rarely changed : : and fixed within sery small range, and we are usually interested in the behaviour of the sy:tem in the vicinity of this steady-state, linear approximation is usual y valid. Use of Tinearized equations also facilitates the use; : of transfer function representation.

Assuming that an adequate modelling of the heater can be represented by a second order model with a major time constant $T_{1}$ and a minor time constant : : T2 plus dead time $\theta_{p}$, then

$$
\vdots \quad H_{p}=\frac{k_{p} e^{-\theta} p_{p}}{\left(T_{1} s+1\right)\left(T_{2} s+1\right)}
$$

Temerature sensor(usually thermocouple immerged in a thermowell)can be mod- : : elled adequately using another second order element with $T_{m p l}$ and $T_{m p 2}$ as
major and minor time constants respectively. Thus,

$$
H_{m p}=\frac{K_{m p}}{\left(T_{m p 1}+1\right)\left(T_{m p 2}+1\right)}
$$

$\vdots$ A secondary measurement element(implemented in cascaded control system as either pressure sensor or flow sensor) can be modelled using first order element.

$$
w_{m s}=\frac{k_{m s}}{\left(r_{m s} s+1\right)}
$$

The actuator or the control valve can be adequately represented by a first order model as follows:

$$
W_{v}=\frac{K_{v}}{\left(T_{v} s+1\right)}
$$

The following Pade approximation [4] is used to sinulate time delay elements: 


$$
e^{-\theta_{p} s}=\frac{1-\theta_{p} s / 2}{1+\theta_{p} s / 2}
$$

Where $\theta_{p}$ is the delay time.

\section{CONTROLLING SYSTEMS}

When a disturbance hits a crude oil heater under PID controlling action in a single feedback loop, the process is under no control until the disturbance effect appears in the oil temperature output. Therefore, the process behaviour under simple feedback alone can be not satisfactory in a slow response proc-: :ess as the one under investigation, and much more complicated(multiloop) systems are usually needed.

\section{:Cascaded Contrōl}

The technique of cascaded control has been used in temperature control of crude $0 i 1$ heaters for many years. It minimizes the effect of disturbances entering the cascaded loop, speeds up the response of the control system, and thus improves the performance of the overall system. Intuitively, it should be clear: that the inner loop must be at least as fast as the outer loop if the cascade is to be effective. The ratio between the time constants from the primary loop and secondary loop is recommended by [5] to lie between 5 and 10. The primary: controller has been assumed in our study to be the standard PID action, as the case in most practical control systems $[6,7]$, with the parameters $K_{c p}, T_{i p}, T_{d p}$ need to be tuned properly. Thus,

$$
\vdots \quad W_{c p}=K_{c p}\left(1+\left(1 / T_{i p} s\right)+T_{d p} s\right)
$$

The secondary controller has been assumed to be standard PI action, with the : following transfer function, to obtain better performance for fast and noisy measured secondary variable(pressure or flow)[ 8].

$$
W_{C S}=K_{C S}\left(1+\left(1 / T_{i s} s\right)\right.
$$

Fig. 1 (a,b) illustrates the biock diagram of cascaded control system and sho-: : ws different ways for applying the block diagram of cascaded control system and shows different ways for applying this technique on crude oil heaters.

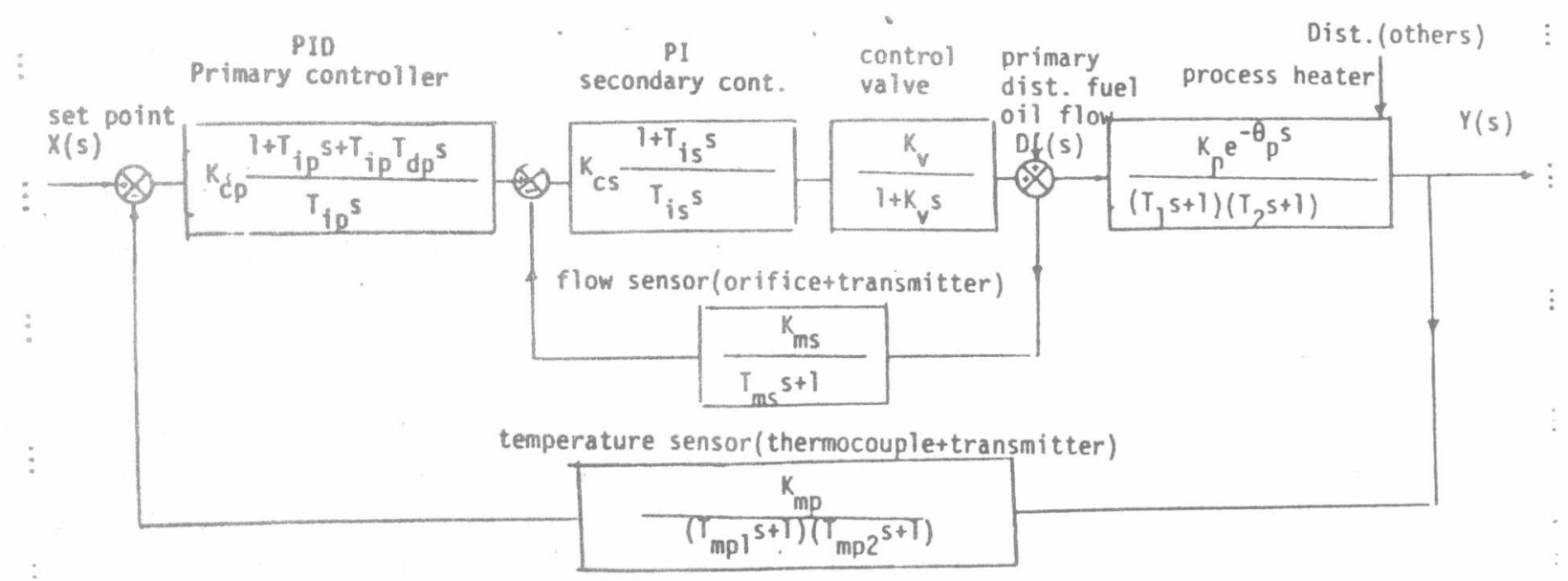

Fig. $(1-a)$ 
The transfer function of the secondary loop $\mathrm{W}_{\mathrm{s}}$ is

$$
W_{s}=\frac{W_{c s} W_{v}}{1+W_{m s} W_{c s} W_{v}}
$$

While the transfer function of the tran system is

$$
\frac{y}{x}=\frac{W_{c p} W_{s} W_{p}}{1+W_{m p} W_{C p} W_{s} W_{p}}
$$

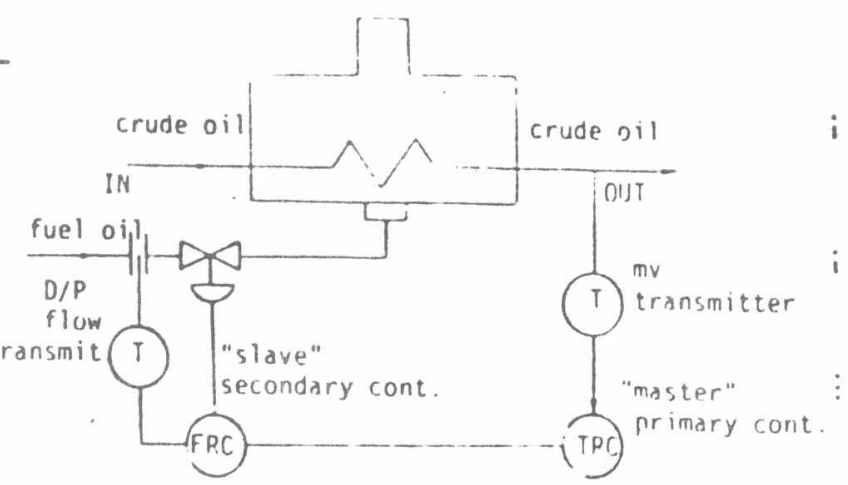

1) TPC,FRC cascade control inon

\section{Preview Contro?}

Preview control is the application of a controlling action to a process before a diviation occurs in the controlled variable due to uncontrolled variable disturbanse. In process crude oil heaters, preview control can be implemented to counteract the disturbances caused due to change of fuel gas press. ure or flow rate. The Preview controlling action reduces the lag time

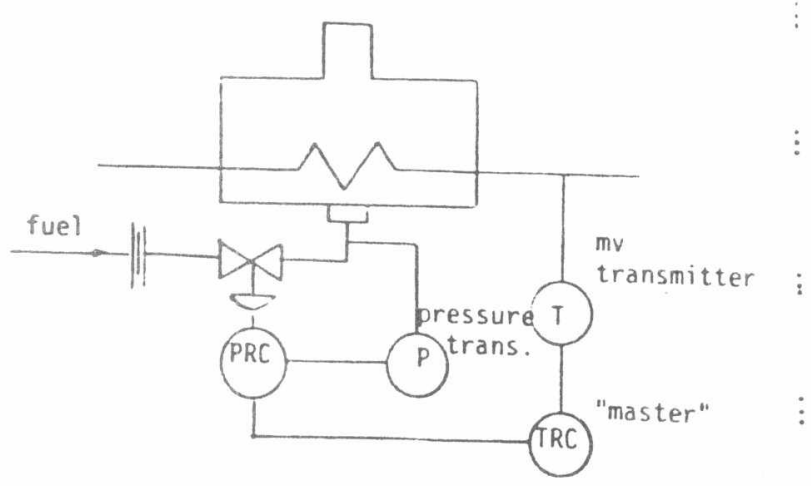
to a satisfactory range. The simplest 2) TRC/PRC cascade control loop

: form of the preview controlling action is merely proportion however, if there is a difference in the

speed of the process response to the control action compared to that of the disturbance, it may be necessary to introduce some dynamic elements in order to balance things out. Fig.2 illustrates the block diagram of preview control system investigated.

: The transfer function of the feedforward path of control system considering load change is

$$
\frac{Y}{x}=\left(W_{c f} W_{m f}-\left(1 / W_{v}\right)\right) \frac{W_{v} W_{p}}{1+W_{c p} W_{m p} W_{v} W_{p}}
$$

$\vdots$

\section{DIGITAL SIMULATION TECHNIOUIE}

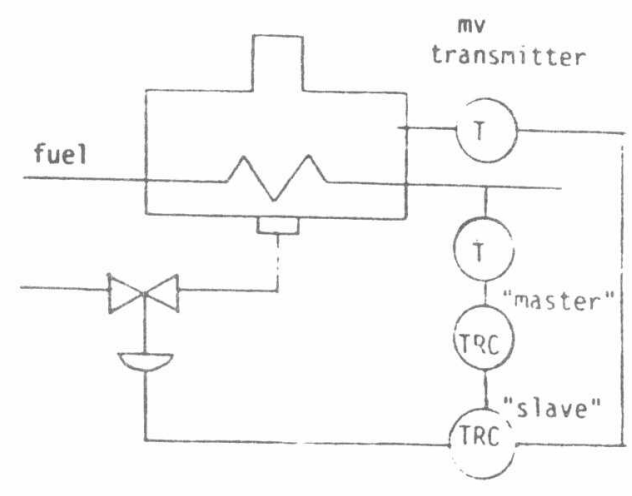

3) TRC/TRC cascade control loop

Fig.(7-b) signal flow diagram for crude oil heater control system.

Digital computer is the most powerful tool for solving differential equations and can provide rapid and reproducable solutions for the analysis of the dynamic performance of oil heater under many controlling actions. Therefore, developing a technique for controllers tuning through system simulation using digital computer was the main objective of the present study. An inter- 


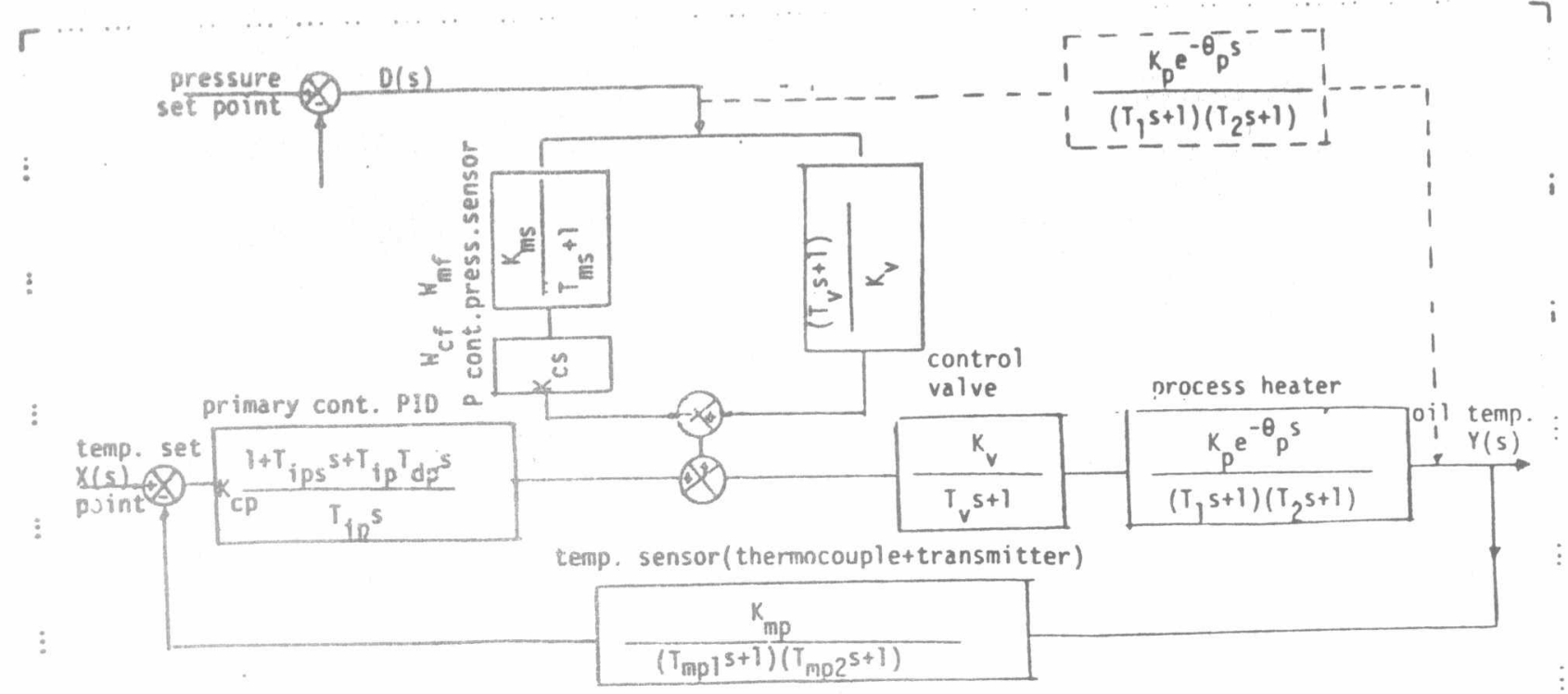

Fig. 2 Block Diagram of Preview Control

active computer package was developed to guide the user through various innuts, block diagram, control parameters, and output ontions. This packane is written in FORTRAN and consists of a section of physical data(given or identi- i fied for on-line use), subprograms to calculate transfer functions and time

responses, output plotting routines, and a master program to monitor the sequence and output the results. The package considers that the oil heater is i controlled through feedback, cascade, and preview controlling actions with the

oportunity to add controllers and construct a multi-loop system has as many blocks as the user wishes.

First, a unit step signal is supplied to the inner loop and the secondary controller is tuned through the digital simulation. Then a unit step input signal is applied to the overall system and the PID parameters are obtained The tuning is based on a maximum overshoot 1.16 of the set point [9] and minimum transient response time(setling time). Two locations have been consider . ed for input signal to detune the controller;pronerly(a) at the set point(b) at the major disturbance input. Once the computer packag is set up, we no longer need to consider individual cases or try to solve their differential equations. The controller parameters can easily adjusted to amalgamate changes in the process under study or the inforced constraints or even to make the system follow certain transient response characteristics using MARS [0].

\section{RESULTS AND DISCUSSION}

: About 250 cases have been studied to obtain the effect of changing every controller parameter on the system response. This study has been concentrated on a process which has major time constant within(1.5-2.0)min., and minor

time constant of (1.0-1.5)min. to cover time constant values of most crude oil heaters in practice.Typical time constant values are also considered for sensing elements and actuators in the loop and they are $T_{\mathrm{mpl}}=(0.55-0.65) \mathrm{min}$. $T_{m p 2}=(0.25-0.35) \mathrm{min} ., T_{\mathrm{ms}}=(0.25-0.35) \mathrm{min}$, and $T_{v}=(0.45-0.5) \mathrm{mpl}$ min. Figs $(3-5) i 11-$ userate typical results for the effect of $K^{m}, T_{i n}$, and $T$ on the system response due to unit step input.Fig.6 indicfles that smal9er overshoot and setling time are obtained for the same controller settings after adding the cascade loop. 


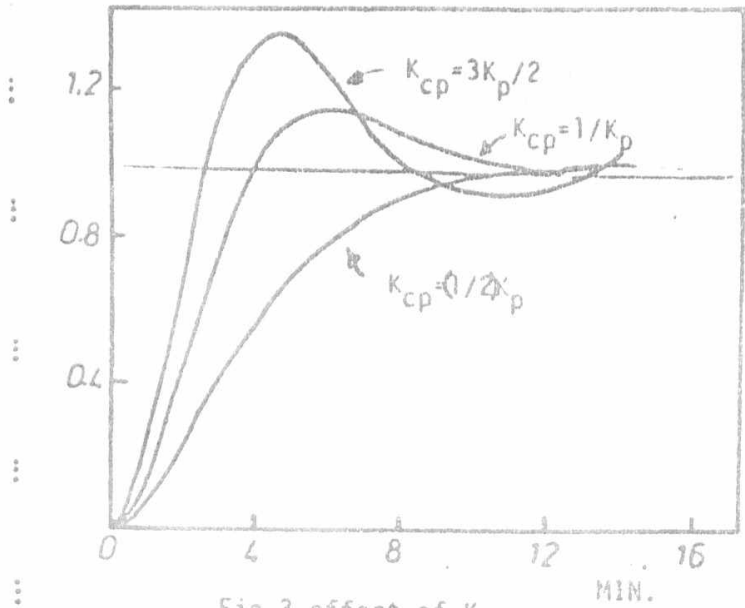

Fig. 3 effect of $K_{c p}$

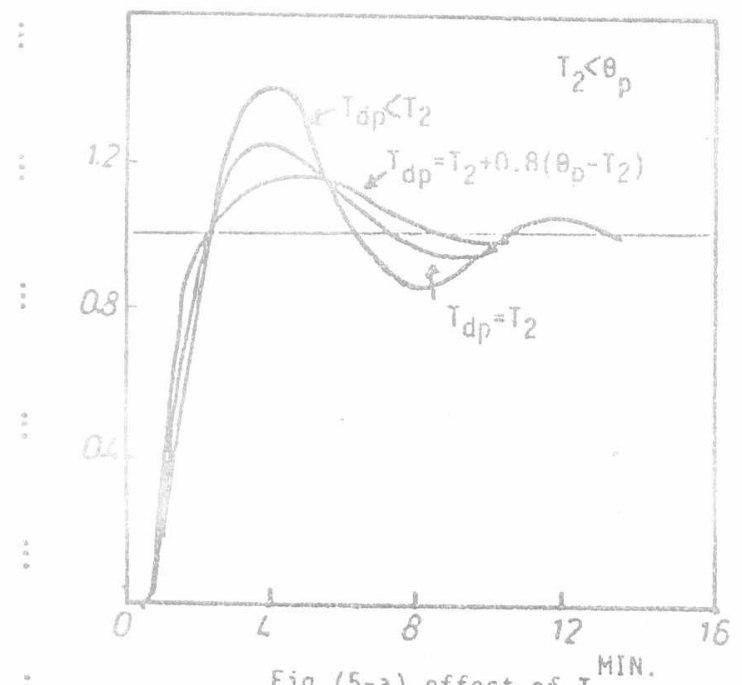

$\vdots$

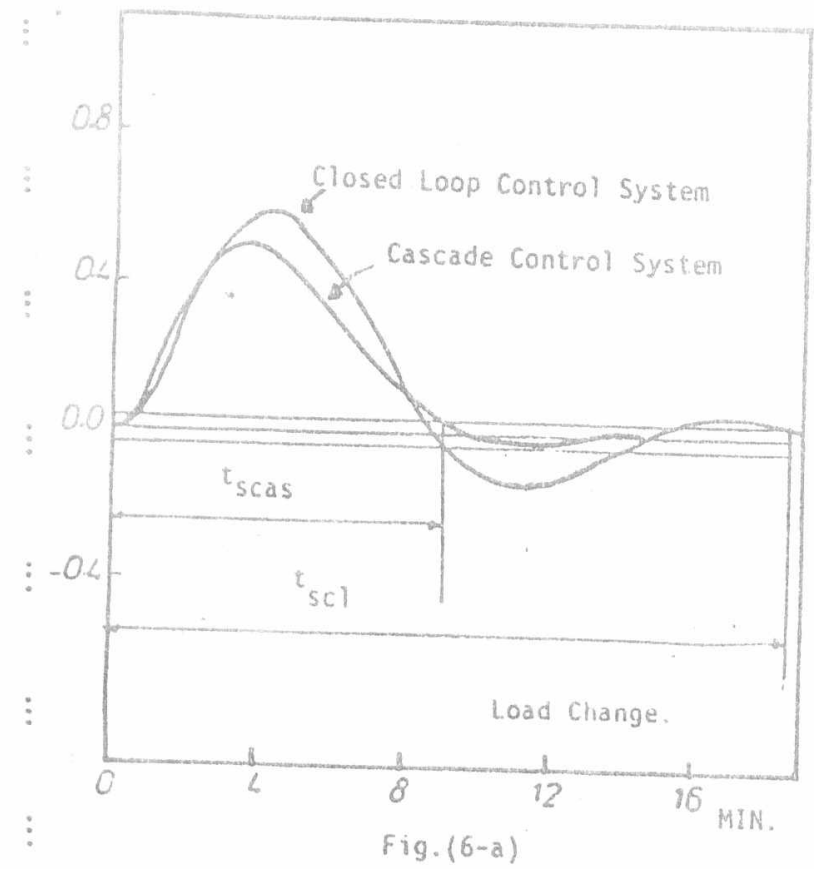

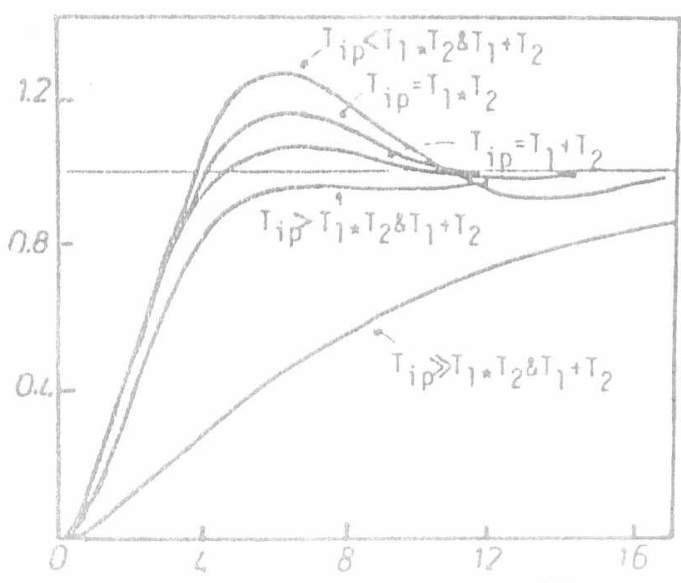

Fig. A effect of $T_{\text {ip }}$

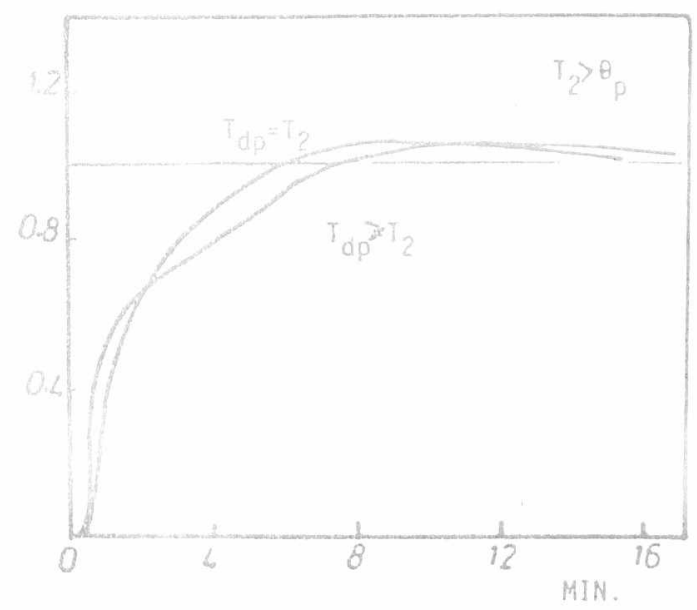

Fig. $(5-b)$ effect of $T d p$

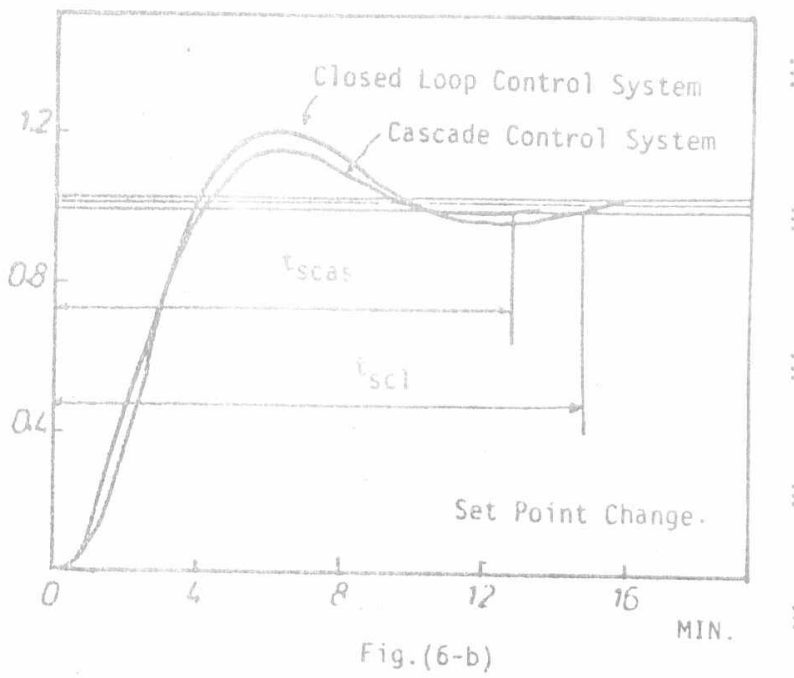

L. 
The following guidelines and recommendations have been obtained or justified for oil heater controller tuning:

1-The simulation work clearly favors installation of cascade control acti-

on.

2-Preview of future system disturbances is shown to be effective to impro- $i$ ve the performance of the control system.

3-It is important to keep the integral band of the secondary controller $T_{\text {is }}$ as minimum as possible and must be less than any time constant in the systeni. systenl.
- The proportional gain $K$ must be kept at a maximum value within the sta-
ble range of the secondary loop.

5-The most suitable gain for the PID action of the primary controller is

: of the order of the inverse of the process gain,

$$
\text { i.e } \quad k_{C p} \approx 1 / k_{p}
$$

6-An integral time constant within the range,

$\vdots \quad T_{1} * T_{2} \leqslant T_{i p}<T_{1}+T_{2}$

gives very good performance.

7-The derivative time constant $T_{p}$ has almost no effect on the performance of the system unless the system has a dead time. Recommended values of

$T_{d p}$ in such cases can be put in the following form:

$\vdots$

$$
\mathrm{dp}_{\mathrm{p}}=\mathrm{T}_{2}
$$$$
\text { for } \quad T \geqslant \theta_{p}
$$

And

$$
\operatorname{tap}_{2}=\frac{5}{2}+0.8\left(\phi_{\mathrm{p}}-\tau_{2}\right) \text { for } \tau_{2} \text { ? }
$$

In order to verify the proposed method for controller-tuning, controller parameters obtained through digital simulation technique have been implemented ch a physical oil heater of Cairo 0il Refining Co., in Mostorod.

: The process parameters have been identified using the reaction curve method [1] , and it was found to have the transfer function:

$$
u_{p}=\frac{2.43 \mathrm{e}^{-2 s}}{(1.8 s+1)(1.45 s+1)}
$$

Closed-10op response of the physical plant under control actions after the application of an artifitial disturbances(a typical resul is shown on fig. 7 ) shows substantial improvement and thus, justify digital simulation in

: assessment of controller parameters.

Comparison of the simulation response and the experimental response shows they are almost identical excent for a small discrepancies which is less than $15 \%$ in overshoot and $18 \%$ in setling time, due to the nonlinearties and signal transmission losses of the system.

A comparative study between the results obtained through digital simulation tichnique and the controllers determined using previous methods is also carried out and typical values are given in Tables 182 


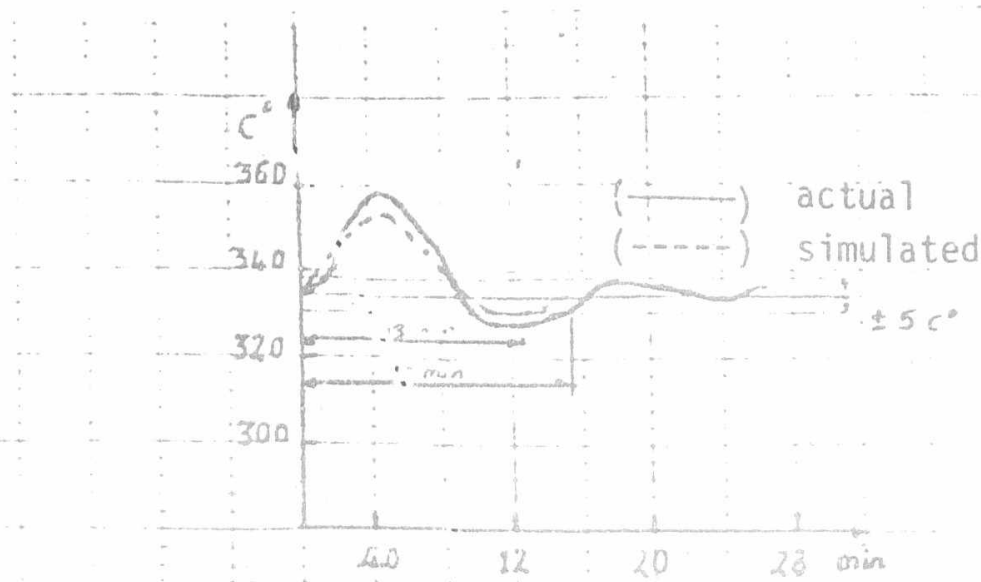

Fig. 7

Fig.7 oil heater response under estimated parmeters using digital simulation.

Table 1 Single Feedback Loop Parameters Settings.

\begin{tabular}{|c|c|c|c|c|}
\hline Controller & \multicolumn{3}{|c|}{ Method of Tuning } \\
\cline { 2 - 5 } Parameters & $\begin{array}{l}\text { Proposed Technique Using } \\
\text { Digital Simulation }\end{array}$ & Z.N & ITAE & GROVE [12] \\
\hline$K_{C}$ & 0.5 & 6 & 4.2 & 0.22 \\
$T_{i} \min$ & 2.7 & 1.5 & 4.0 & 1.8 \\
$T_{d} \min$ & 1.9 & 0.4 & 0.6 & 1.6 \\
\hline
\end{tabular}


FIRST A.M.E. CONFERENCE

$r$

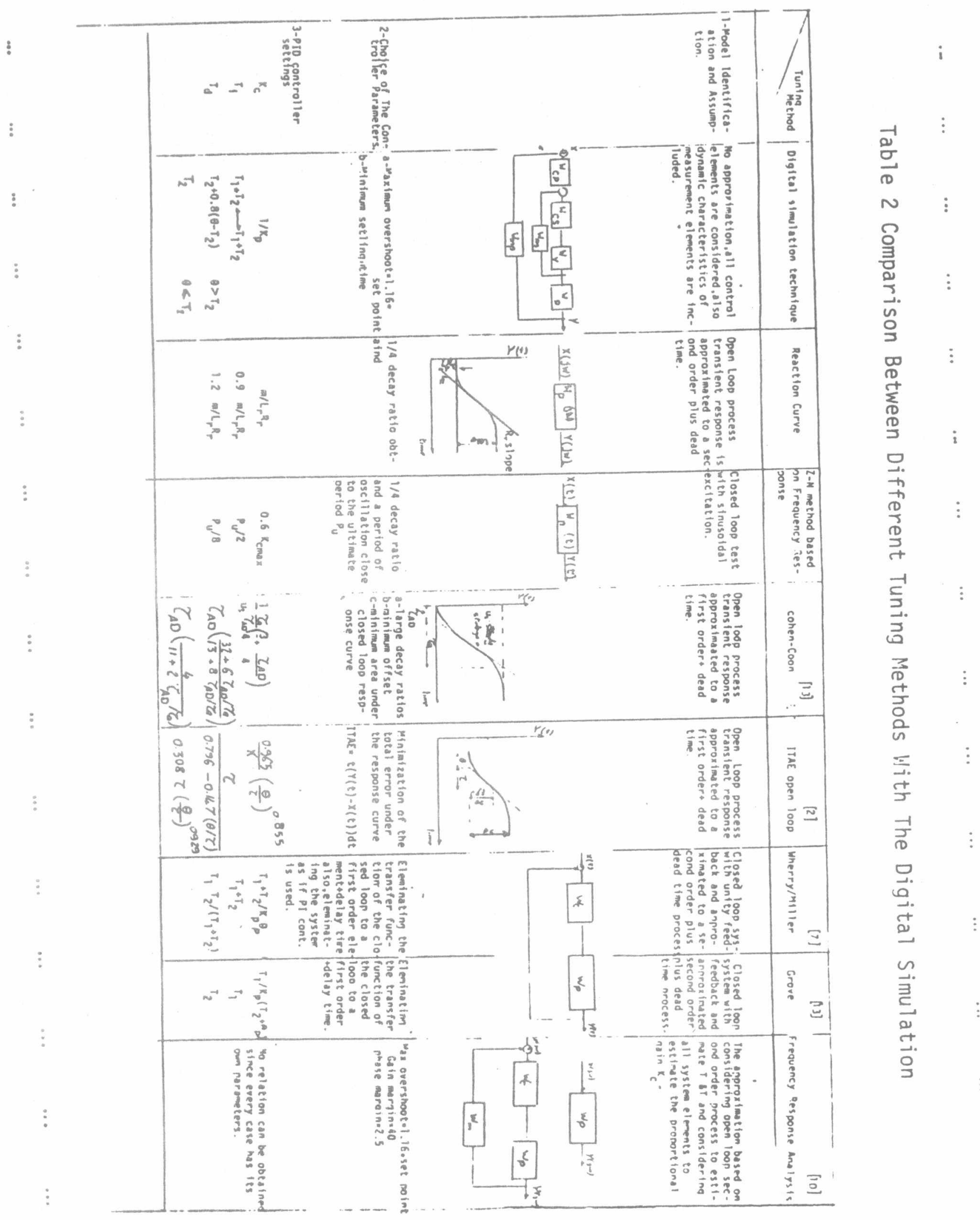




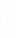
CONCLUSIONS

Digital simulation technique was proposed and investigated for estimating controller parameters of a crude 011 heater to reduce, as much as possible, time lags, reject disturbances effects, and yield acceptable performance. : The proposed technique can consider multi-loop control system with cascade and Preview controllers. Controller structure may include P, PI, PID actions. It was found that cascade control reduces substantially the effect of the : time delays, and that the preview of disturbances drastically improves the performace of the system. The experimuntal study has established that the digital simulation technique is the most promising technique available for: controllers tuning especially for multi-loop and complicated systems. Al though "OFF-Line" study have been conducted in al1 cases, the proposed technique is potentially more useful and applicable to "ON-Line"operation.:

A comparative investigation has been carried out between the controller parameter settings obtained using the proposed technique and other methods. The proposed technique results show to give outstanding performance and : flexibility in the design of controlling system were never been able to obtain before.

\section{REFEPERCES}

T.Ziegler, J.G.and Pichols, H. B. "Optimum settings for Automatic Contro- i llers" "Trans. AsMi, $11,759,(1942)$.

2. Rovira, A. A. and others, "Tuning Controllers for Set Point Changes", Ins and Control System.12.(1969).

3.Dahtin, F.B., "Designing and Tuning Digital controllers.", Ins. and Control Systems,6,77,(1968),7,87-91,(1968).

4. Truxal, J.G. "Automatic Feedback Control System Synthes is". McGrawHill co. New York(1955).

5. Verchaegen, C.C. "Temp. Cascaded Best Heater Control" ,Process Ins. Manual, Gulf Publishing Co., $37,(1968)$.

6. Wherry, T.C. and others, "Chemical Engineers Handbook" "McGraw-Hill co. ,Kogakusha, 22,21, (1973).

7. Hougen, J.0, "l. Measurements and Control Application", 1SA, USA, 329, (1979).

8. Harriott.P., "Process Control" "McGraw-Hill Co: New York, 158, (1979).

9. Hengstebeck, R.J. "Petroleum Processing", McGraw-Hill co. ,New York, (1959), and Cairo 011 Refining co, chemical Lab. Reports.

10.Zaghloc1, S.A. "System Identification Via Families of Digitai Algorithms", Int. J.Contro1,34,685-712,(7981).

11. Anderson, N.A. "Instrumentation for Process Pleasurement and Control" ",
Chilton Book Co. "Pensylvania, 127, (1975).

12. Groves, E. R"New Ideas In Practical Control Schemes and Tuning Techniques", ISA Trans. Vol 17. No 2, (1978). 13. Cohen,G.H. and Coon, G.A. "Theoretical Consideration of Retarded Cont-
rol." "Trans. ASME 75,827(1953). 